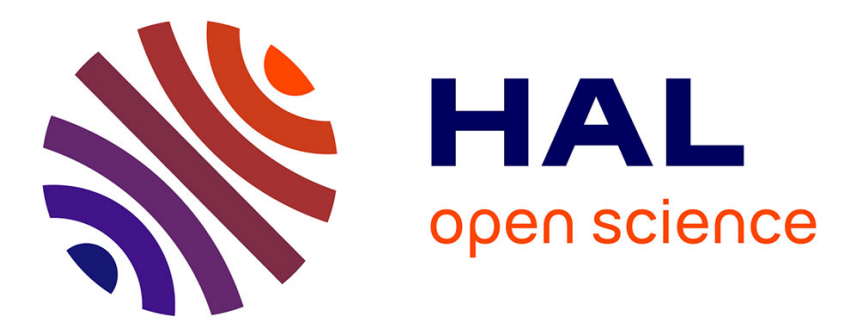

\title{
Psychological adjustment and autonomic disturbances in inflammatory bowel diseases and irritable bowel syndrome.
}

Sonia Pellissier, Cécile Dantzer, Fréderic Canini, Nicolas Mathieu, Bruno

Bonaz

\section{To cite this version:}

Sonia Pellissier, Cécile Dantzer, Fréderic Canini, Nicolas Mathieu, Bruno Bonaz. Psychological adjustment and autonomic disturbances in inflammatory bowel diseases and irritable bowel syndrome.: Psychological and autonomic dysfunctions in IBD and IBS. Psychoneuroendocrinology, 2010, 35 (5), pp.653-62. 10.1016/j.psyneuen.2009.10.004 . inserm-00528271

\section{HAL Id: inserm-00528271 https://www.hal.inserm.fr/inserm-00528271}

Submitted on 10 Feb 2012

HAL is a multi-disciplinary open access archive for the deposit and dissemination of scientific research documents, whether they are published or not. The documents may come from teaching and research institutions in France or abroad, or from public or private research centers.
L'archive ouverte pluridisciplinaire HAL, est destinée au dépôt et à la diffusion de documents scientifiques de niveau recherche, publiés ou non, émanant des établissements d'enseignement et de recherche français ou étrangers, des laboratoires publics ou privés. 


\section{Psychological adjustment and autonomic disturbances in inflammatory bowel diseases and irritable bowel syndrome}

Sonia Pellissier ${ }^{\mathrm{a}}$, Cécile Dantzer ${ }^{\mathrm{b}}$, Fréderic Canini ${ }^{\mathrm{a}, \mathrm{c}}$, Nicolas Mathieu$^{4}$, and Bruno Bonaz ${ }^{\mathrm{a}, \mathrm{d}^{*}}$

${ }^{\mathrm{a}}$ Stress et Interactions Neuro-Digestives (SIND), Grenoble Institut des Neurosciences (GIN), Centre de Recherche INSERM 836 UJF-CEA-CHU, Grenoble, F-38043, France

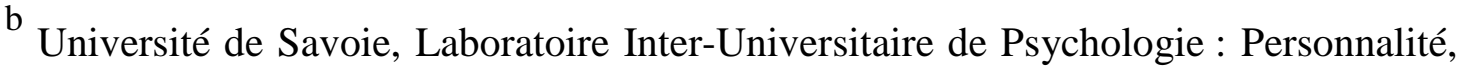
Cognition, Changement social (LIP/PC2S), Chambéry, BP 1104, F-73011, France

c Département des Facteurs Humains, Pôle de Neurophysiologie du Stress, Centre de Recherches du Service de Santé des Armées Emile Pardé, 24 Avenue des Maquis du Grésivaudan, F-38702 La Tronche Cedex, France

d Clinique Universitaire d’Hépato-Gastroentérologie, CHU de Grenoble, F-38043, France

Running title: Psychological and autonomic dysfunctions in IBD and IBS

* Corresponding author at: Clinique Universitaire d’Hépato-Gastroentérologie et Stress et Interactions Neuro-Digestives (SIND), Grenoble Institut des Neurosciences (GIN), Centre de Recherche INSERM 836 UJF-CEA-CHU, Grenoble, F-38043, France. Tel.: +33 4 76765597; fax: + 33476765297 .

E-mail address: BBonaz@chu-grenoble.fr (B.Bonaz) 
Summary Psychological factors and the autonomic nervous system (ANS) are implicated in the pathogenesis of inflammatory bowel diseases (IBD) and irritable bowel syndrome (IBS). This study aimed to assess, firstly the way IBS and IBD patients cope with their pathology according to their affective adjustment and secondly the possible links between these affective adjustments and ANS reactivity. Patients with Crohn's disease (CD; $n=26$ ), ulcerative colitis (UC; $n=22$ ), or IBS ( $n=27$ ) were recruited and compared to 21 healthy subjects based on psychological variables (trait- and state anxiety, depressive symptomatology, negative mood, perceived stress, coping, health locus of control) and sympatho-vagal balance through heart-rate variability monitored at rest. A principal component analysis, performed on all affective variables, isolated a leading factor labelled as “affective adjustment”. In each disease, patients were distributed into positive and negative affective adjustment. In all the diseases, a positive affect was associated with problemfocused coping, and a negative affect with emotion-focused coping and external health locus of control. Results show that the sympatho-vagal balance varied according to the disease. In CD presenting positive affectivity, an adapted high sympathetic activity was observed. In UC, a parasympathetic blunt was observed in the presence of negative affectivity and an equilibrated sympatho-vagal balance in the presence of positive affectivity. In contrast, in IBS, an important dysautonomia (with high sympathetic and low parasympathetic tone) was constantly observed whatever the affective adjustment. In conclusion, this study suggests that the equilibrium of the ANS is differentially adapted according to the disease. This equilibrium is conjugated with positive affective and cognitive adjustment in IBD (CD and UC) but not in IBS. 
S. Pellissier et al. Psychological and autonomic dysfunctions in IBD and IBS

KEYWORDS: $\quad$ Inflammatory bowel diseases (IBD); Irritable bowel syndrome (IBS);

Coping; Emotion; Heart rate variability (HRV); Autonomic nervous system (ANS) 


\section{Introduction}

Inflammatory bowel diseases (IBD) are primarily comprised of 2 disorders: ulcerative colitis (UC) and Crohn's disease (CD). IBD are characterized by a chronic course in which phases of remission of variable length are interrupted by acute episodes. Irritable Bowel Syndrome (IBS) is a highly prevalent functional gastrointestinal disorder mainly characterized by abdominal pain and discomfort in association with altered bowel habits in the absence of any structural abnormalities (Schepper et al., 2008; Thompson et al., 2000; Thompson et al., 1999). Despite differences in the aetiologies of IBD and IBS (Baumgart and Sandborn, 2007; Von Stein et al., 2008) stress represents a common risk factor in their pathogenesis. Patients often report stressful life events at the onset and/or during the time course of their disease (Collins, 2001; Li et al., 2004; Mawdsley and Rampton, 2005; Mönnikes et al., 2001; Reber et al., 2006; Tang et al., 2008). The burden of such chronic diseases adds undercurrents of psychological strain to the weight of the pathology. Most of the psychological disturbances reported in IBD and IBS are therefore principally related to the illness' time course (Jones et al., 2006). It results in high perceived stress levels (Rogala et al., 2008; Tang et al., 2008), impaired quality of life (Coffin et al., 2004) and affective co-morbidities such as worries, anxiety, negative mood or depression (Miehsler et al., 2008; Mittermaier et al., 2004; Olden, 2008; Sugaya and Nomura, 2008). This forces the patients to develop coping strategies such as i) problem-focused coping (i.e., where the individual faces the problem, seeks a solution, tries to resolve it), ii) emotion-focused coping (i.e., where the individual changes by denying that there is a problem to be able to cope with) and iii) search for social support (i.e., where the individual asks his family or health professionals for help, or counselling). These coping strategies may in turn influence the path of their disease: CD patients with low avoidance coping strategies were the least likely to relapse (Bitton et al., 2008). The individual coping style may therefore determine the outcome, which combines psychological (e.g., anxiety, 
depression), social (e.g., absenteeism, social withdrawal) and biological (e.g., evolution of the disease) dimensions. This is commonly observed in multiple chronic diseases (such as arthritis or heart disease) in which problem-focused coping or search for social support is usually more beneficial than emotion-focused coping (Martz and Livneh, 2007; Thompson and Gustafson, 1996). This point of view agrees with the Lazarus \& Folkman’s transactional model of stress in which stress is considered as the result of an "imbalance between demands and resources” occurring when "pressure exceeds one's perceived ability to cope” (Lazarus and Folkman, 1984). It could be speculation then, that the extent of positive affects influence coping in favour of beneficial ways (i.e. problem-focused and social search coping).

The interrelations between digestive diseases and psychological disturbances reflect the special link between the brain and the gut in what is called the "brain-gut axis". The autonomic nervous system (ANS) is the neural interface relaying bottom-up and top-down informations. Visceral sensations are carried through vagal afferents. These informations directly modulate efferent premotor regions of the ANS (Craig, 2002; Mayer et al., 2006). More importantly, these efferent regions can also be negatively or positively modulated by a set of upper brain regions like amygdala, hippocampus and prefrontal cortex (Benarroch, 1993; Loewy and Spyer, 1990; Saper, 2002). These regions which can modulate gut function, are also involved in the regulation of emotional (e.g., mood, anxiety, negative affects, pain) and cognitive behaviours (e.g., decision making, planning, search for informations), and therefore in the development of social behaviour, coping strategy and well-being (Gillanders et al., 2008; Seminowicz et al., 2004). Accordingly, a growing body of evidence suggests the existence of autonomic dysfunctions in patients with IBD and IBS (Ollsson et al., 2007; Spaziani et al., 2008; Spetalen et al., 2008; Taylor and Keely, 2007; Van Orshoven et al., 2006), whatever the severity of symptoms and even during remission in IBD or asymptomatic phase in IBS (Ganguli et al., 2007; Sharma et al., 2008). Despite these findings, little is 
known about the type of autonomic dysfunctions according to the way patients are psychologically adjusted with negative or positive affects. We speculate that the positive or negative affects observed in IBD and IBS patients are associated to specific coping strategies (more problem-centred in the positive affects cases or more emotion-centred in the negative affects cases) and to an adapted ANS activity (equilibrated autonomic balance in the positive affects cases and an imbalance in the negative affects cases). Since gut diseases are heterogeneous, we have studied these relations in three groups of patients (IBS, IBD with CD or IBD with UC) in comparison to healthy controls. In order to understand the links between emotional affects, coping strategies and ANS adaptations, each group of patients was subdivided into two subgroups according to their emotional adjustment. Differences in coping style and ANS balance were analyzed in these two subgroups. 


\section{Materials and Methods}

\subsection{Subjects (Table 1 , subject demographics)}

Ninety-six subjects were prospectively recruited between January $1^{\text {st }}$, 2006 and December $31^{\text {st }}, 2007$. All patients were recruited in our Gastroenterology Department while age- and sex-matched healthy subjects were included from the Grenoble Inserm Clinical Investigation Centre. Subjects were distributed as: i) Healthy volunteers (controls, n=21), ii) IBS patients ( $\mathrm{n}=27$ ), iii) IBD patients ( $\mathrm{UC}, \mathrm{n}=22 ; \mathrm{CD}, \mathrm{n}=26$ ). The study was conducted according to the Declaration of Helsinki and in accordance with the guidelines of Good Clinical Practice. The protocol was approved by the ethical committee of the Grenoble Faculty of Medicine and Hospital (France) and written informed consent was obtained from each participant.

\subsection{Criteria for inclusion}

\subsubsection{IBD patients}

CD patients were selected according to their phenotype as defined by the Vienna classification (Gasche, 1998). CD patients with isolated ano-perineal or upper digestive tract lesions were not eligible. CD activity was evaluated by the Harvey-Bradshaw index (HBI, (Harvey and Bradshaw, 1980) and patients with an $\mathrm{HBI}>4$ on inclusion were considered under clinical relapse. UC patients with lesions limited to the rectum were not eligible. UC activity was evaluated by the ulcerative colitis activity index (UCAI; Lichtiger et al., 1994) and patients with a UCAI $\geq 10$ were considered to have a clinical relapse.

Concomitant treatments (e.g., date of start, duration, stable dose, mean dose) were recorded. Patients were included only if they had a stable dose of i) 5-aminosalicylates for at least 2 weeks, ii) corticosteroids for at least 2 weeks, iii) immunosuppressives (e.g., 
azathioprine/mercaptopurine, methotrexate) for at least 12 weeks, and iv) biological therapy (e.g., infliximab, adalimumab) for at least 8 weeks.

\subsubsection{IBS patients}

Patients were selected according to Rome II criteria (Thompson et al., 1999): at least 12 weeks, not necessarily consecutive, in the preceding 12 months of abdominal discomfort or pain that has two out of three features: 1) Relieved with defecation; and/or 2) Onset associated with a change in frequency of stool; and/or 3) Onset associated with a change in form (appearance) of stool. Patients who had previously undergone abdominal surgery, except appendectomy and/or cholecystectomy, were excluded from the study. The severity of disease was estimated through the completed standardized bowel disease questionnaire (Coffin et al., 2004) and a visual analogic scale (VAS) measuring the intensity of perceived pain the day of HRV assessment. The lack of organicity for patient's symptoms was assumed through: i) a negative physical examination; ii) a normal colonoscopy performed within the last five years with normal biopsies (i.e., absence of microscopic colitis); iii) normal limited laboratory evaluations with a lack of inflammation (i.e., erythrocyte sedimentation rate, C-reactive protein), anaemia and infection (complete blood cell count) and endocrine or metabolic disturbances (i.e., thyroid stimulating hormone, chemical analysis).

\subsection{Criteria for exclusion}

Patients were excluded from the study if: (i) they did not fulfil the regulatory conditions; (ii) they had past or present medical conditions complicated by autonomic dysfunction (e.g., peripheral neuropathy, diabetes, vagotomy, dysthyroidism, amyloidosis, asthma, heart failure, renal insufficiency, alcoholism), psychiatric disorders (e.g., panic disorder, uncontrolled depression), (iii) they were under medication susceptible to modify the ANS (e.g., anticholinergics, antiarrhytmics, clonidine, beta blocking agents, tricyclic antidepressants, 
metronidazole). Smokers were asked to abstain from smoking on the morning of their testing session.

\subsection{Experimental design}

All patients underwent an interview concerning their history (disease duration, extent, extraintestinal manifestations, course, current and past therapies, past medical history, medications) and a physical examination in order to determine their inclusion in the study according to the defined criteria described above.

After enrolment, the patients came one at a time in the Department of Gastroenterology. Upon their arrival, patients were led into a quiet examining room and asked to sit down in a comfortable armchair. After a 30-min period of relaxation, patients underwent a 10-min ECG assessment during which the technician carefully observed the optimal condition to ensure that recording was free of body movements, conversations, and any subjective discomfort. After ECG recording, patients responded to psychological questionnaires in a separate quiet examining room for 30 to $45 \mathrm{~min}$. All experimental sessions were performed between 8 AM and 12 AM.

\subsection{Autonomic assessment: Power spectral analysis of Heart Rate}

\section{Variability}

ANS activity was explored using heart rate variability (HRV) as a reliable and non invasive method to assess sympatho-vagal balance (Lombardi et al., 1996). Initially described by Akselrod (Akselrod et al., 1981) to explore cardiovascular control, this tool is now commonly used in gastrointestinal physiology to assess autonomic imbalances related to digestive autonomic regulation (Chen et al., 2004; Chen et al., 2006; Jarrett et al., 2008; Ng et al., 2007; Petelenz et al., 2004). ECG signal was acquired through electrodes placed on each wrist. HRV 
analysis was performed with specific software (Heart Rhythm Scanner, Biocom Technologies, USA). Firstly, QRS complexes were automatically classified. Ectopic or abnormal QRS complexes and noise were automatically removed. The signal was then carefully checked and remaining abnormalities were manually removed. Then, a standard spectral analysis was applied on inter-beat intervals by means of Fast Fourier Transformation (FFT). The following parameters were calculated: (i) Total Power (TP, from 0 to $0.4 \mathrm{~Hz}$, $\mathrm{msec}^{2}$ ) was considered as the net effect of all physiological mechanisms contributing to HRV; (ii) High Frequency power spectrum (HF, from 0.15 to $0.4 \mathrm{~Hz}, \mathrm{msec}^{2}$ ) reflected both parasympathetic and fluctuations caused by respiratory sinus arrhythmia; (iii) Low Frequency power spectrum (LF, from 0.04 to $0.15 \mathrm{~Hz}, \mathrm{msec}^{2}$ ) reflected both sympathetic and parasympathetic tone; (iv) Very Low Frequency power spectrum (VLF, from 0.0033 to $0.004 \mathrm{~Hz}, \mathrm{msec}^{2}$ ) might represent various negative emotions or worries in short time recording (Yeragani et al., 1998). These variables were then expressed in normalized units: normalized VLF (VLFn) was calculated as the ratio of absolute values VLF/TP-(LF+HF) and the same was carried out for normalized HF [HFn, HF/(TP-VLF)] and normalized LF [LFn, LF/(TP-VLF)]. This calculation minimized the effect of changes in Very Low Frequency power or LF and HF power and emphasized the changes in sympathetic or parasympathetic regulation. (v) Lastly, LF/HF ratio was calculated as a global marker of the balance between sympathetic and parasympathetic tones.

\subsection{Psychological assessments}

Anxious symptomatology was assessed using the trait version of the State-Trait Anxiety Inventory (STAI; Spielberger et al., 1983), validated in French by Bruchon-Schweitzer and Paulhan (Bruchon-Schweitzer and Paulhan, 1993). It differentiates the more general and longstanding quality of "trait anxiety" from the temporary condition of "state anxiety". It consists of two scales with 20 items each, with a score varying from 20 to 80, a high score indicating 
high anxiety. In the present sample, the internal consistency was high in both scales (stateanxiety scale: alpha=0.93; trait-anxiety scale: alpha=0.90).

Depressive symptomatology was assessed by the Center for Epidemiologic StudiesDepression Scale (CES-D; (Fuhrer and Rouillon, 1989; Radloff, 1977). This brief scale (20 items) assesses symptoms or behaviours often associated with depression. The total score varies from 0 to 60, a high score signifying a high level of depressive symptomatology. An alpha coefficient for internal consistency of 0.85 has been reported in general population samples and 0.90 in psychiatric samples (Nunnally, 1978). In the present sample, the alpha coefficient was 0.92 .

Perceived stress was evaluated by the Perceived Stress Scale (PSS; (Cohen, 1983), which corresponds to the transactional definition of stress proposed by Lazarus et Folkman where a situation is perceived as stressful if it is perceived as threatening, unpredictable and uncontrollable (Lazarus and Folkman, 1984). This 14-items PSS version presents the best psychometric qualities. Each item is coded for the preceding one-month period from 1 « never » to 5 « often ». A global stress intensity score is calculated from 14 to 70 , a high score signifying high stress intensity. In the present sample, the alpha coefficient was 0.80 .

Negative mood was assessed with the negative mood subscale of the Positive And Negative Affect Scale (PANAS; (Watson et al., 1988a). The response of clinical or normal subjects on pleasant and unpleasant emotional content followed a 2-factor structure with pleasant terms (e.g., being enthusiastic, active) called "positive affect” and unpleasant terms (e.g., sadness, distress, hostility, worry) called "negative affect”. The latter, often considered as a general indicator of psychological distress, is composed of depression, anxiety and neurosis. The balance between both factors is evaluated through 20 emotional states (10 positive and 10 negative). For each state, the patients indicate how they felt during the last month on a 5-point Lickert scale (from « not at all » to « very often »). The score for negative affect vary from 10 
to 50, a high score meaning a high negative affect. In the present sample, the alpha coefficient was 0.82 for the negative affect scale.

Coping strategies were measured by the Ways of Coping Checklist Revised (WCC-R; (Vitaliano et al., 1985), validated in French by Cousson et al. (Cousson et al., 1996). The questionnaire is composed of three subscales: (i) problem-focused coping with a total score varying from 10 to 40 (ii) emotion-focused coping (total score from 9 to 36) and (iii) searching social support (total score from8 to 32). For each subscale, a high score indicates a tendency to use the coping strategy. In our sample, the internal consistency for each subscale was $0.79,0.45$, and 0.85 , respectively.

Health locus of control was evaluated with the Multidimensional Health Locus of Control Scale (MHLCS; (Wallston et al., 1978). It provides assessments of internal self-perceived (one scale) and external perceived locus of control (2 scales, "powerful others" indicates the responsibility for the individual's health on healthcare or professionals; and "Chance" indicates that health is under the control of fate or luck). Respondents were asked to answer on a 6-point Lickert scale from «strong disagreement » to «strong agreement ». The total score for each scale varies from 4 to 24 . A high score on the internal scale indicates personal health responsibility and high scores on both external scales indicate no personal health responsibility. In our sample, the internal consistency was 0.45 for internal subscale, 0.67 for “powerful others”, and 0.40 for “chance” subscales.

\subsection{Statistical analysis}

A Principal Components Analysis was first performed to detect a relationship between affective variables (i.e., CES-D, PANAS negative mood, STAI, PSS) and to reduce them into a single robust dimensional axis. The results of an exploratory factor analysis support such as a single-factor solution explaining $73.9 \%$ of the variance. For instance, subjects with low 
affective tonus exhibited high scores in STAI, CES-D, PANAS negative mood, and PSS. All variables had a negative weight on this factor meaning that subjects with low scores on this new variable presented a positive affect and subjects with high scores had a negative affect. Factor scores were then used to categorize subjects in negative or positive affect using Kmeans clustering method based on observations. Two clusters of subjects (Table 2) were therefore identified: subjects with positive affect $\left(\mathrm{CD}^{+}, \mathrm{UC}^{+}\right.$and $\mathrm{IBS}^{+}$patients) and subjects with negative affect (CD-, $\mathrm{UC}^{-}$and $\mathrm{IBS}^{-}$patients).

A complementary analysis was carried out to determine whether the actual activity of the disease, as assessed through disease activity index, in IBD patients or the level of perceived pain in IBS patients, modified acutely both psychological and physiological states, in order to verify if the level of disease activity constituted a bias. No interactions between disease activity variables and variables of interest were observed for UC and IBS patients. In contrast, an interaction between disease activity index and affective adjustment was found for HRV variables for CD patients. Patients with active CD were therefore discarded from the following steps of statistical analysis ( $\mathrm{n}=5$ patients). Moreover, concerning IBS patients, half of them reported diarrhoea but they were equally distributed in both negative and positive affective adjustment groups $\left(\mathrm{Chi}^{2}=1,05 ; \mathrm{dl}=1 ; \mathrm{p}=0.30\right)$.

The last step of the statistical analysis was carried out using a non-parametric test due to low group sizes. For each disease group, Kruskal-Wallis one-way analysis of variance by ranks was used to compare HRV, WCC-R and MHLCS variables among healthy subjects, patients with positive and negative affective adjustment. Then, two by two comparisons were performed between healthy subjects, patients with negative and positive affective adjustment using Man-Whitney U tests. Lastly, comparisons were then made in-between pathologies (CD, UC and IBS), verifying the differences within patients presenting a solely positive affect or a solely negative affect. 
S. Pellissier et al. Psychological and autonomic dysfunctions in IBD and IBS 


\section{Results}

\subsection{Subject demographics}

Ninety-six Caucasians subjects were prospectively included. Patient and healthy subject demographics are detailed in Table 1 . The number of patients under clinical relapse was as followed: (i) 5/26 CD patients; (ii) 6/22 UC patients and (iii) 6/27 IBS patients.

\subsection{Coping, health locus of control and HRV analysis according to positive and negative affective adjustment (Table 3 )}

\subsubsection{CD patients}

Differences among the groups were observed for problem-centred coping $[\mathrm{H}(2$, $\mathrm{N}=47)=7.119240 ; \mathrm{p}=0.028]$ and emotion-centred coping $[\mathrm{H}(2, \mathrm{~N}=47)=9.854478, \mathrm{p}=0.007]$. The $\mathrm{CD}^{+}$patients presented higher problem-centred coping $(\mathrm{p}=0.02)$ and lower emotioncentred coping $(\mathrm{p}=0.01)$ than the $\mathrm{CD}^{-}$patients. Moreover, the groups' scoring varied on the "powerful others" external control scale $[\mathrm{H}(2, \mathrm{~N}=47)=11.13849$; $\mathrm{p}=0.003]$ with both $\mathrm{CD}^{-}(\mathrm{p}=$ $0.008)$ and $C D^{+}(p=0.04)$ sub-groups having higher external scores than the healthy subjects. No differences among the groups were observed for seeking social support, internal control and "chance" external control.

The CD patients differed from the healthy subjects in $\mathrm{LFn}[\mathrm{H}(2, \mathrm{~N}=47)=6.429656 ; \mathrm{p}=0.040]$ and $\mathrm{HFn}[\mathrm{H}(2, \mathrm{~N}=47)=8.504370 ; \mathrm{p}=0.014]$ with $\mathrm{CD}^{+}$patients having lower $\mathrm{HFn}(\mathrm{p}=0.01)$ and higher LFn ( $\mathrm{p}=0.003$ ) levels than healthy ones. In contrast, there was no significant difference in LF/HF ratio, VLFn and HR among groups. No significant differences were found in any HRV variables between the $\mathrm{CD}^{+}$and $\mathrm{CD}^{-}$patients. 


\subsubsection{UC patients}

Differences among the groups were observed for the following coping variables: problem coping $[\mathrm{H}(2, \mathrm{~N}=42)=7.349775 ; \mathrm{p}=0.025]$; emotion coping $[\mathrm{H}(2, \mathrm{~N}=42)=6.289190 ; \mathrm{p}=0.043]$ with $\mathrm{UC}^{-}$patients exhibiting lower problem coping scores than $\mathrm{UC}^{+}$patients $(\mathrm{p}=0.02)$ and higher emotion coping scores than healthy subjects $(\mathrm{p}=0.04)$. The three groups also expressed differences in the health locus of control on the internal scores $[H(2, N=42)=5.902678$; $\mathrm{p}=0.05]$ and «powerful others » external scale $[\mathrm{H}(2, \mathrm{~N}=42)=8.654523 ; \mathrm{p}=0.013]$ with $\mathrm{UC}^{-}$ patients having lower scores on the internal scale $(\mathrm{p}=0.04)$ and higher scores on the "powerful others" external scale $(\mathrm{p}=0.03)$ than the healthy subjects.

Differences among the groups were observed for $\mathrm{HFn}[\mathrm{H}(2, \mathrm{~N}=43)=5.654144 ; \mathrm{p}=0.05]$ with $\mathrm{UC}^{-}$exhibiting lower HFn level $(\mathrm{p}=0.05)$ than the healthy subjects. Although differences among the groups existed for $\operatorname{VLFn~}[\mathrm{H}(2, \mathrm{~N}=43)=6.422795$; $\mathrm{p}=0.040]$, two by two comparisons were not statistically different. There was no difference in LF/HF ratio, LFn and HR among the 3 experimental groups.

\subsubsection{IBS patients}

Differences were observed among the groups for the three coping variables: problem-centred $[\mathrm{H}(2, \mathrm{~N}=48)=13.21082 ; \mathrm{p}=0.001]$; emotion-centred: $\mathrm{H}(2, \mathrm{~N}=48)=10.48181 ; \mathrm{p}=0.005]$ and searching social support $[\mathrm{H}(2, \mathrm{~N}=48)=13.25554 ; \mathrm{p}=0.001]$. IBS ${ }^{-}$patients had lower problem coping scores than the healthy subjects $(\mathrm{p}=0.01)$ and $\mathrm{IBS}^{+}$patients $(\mathrm{p}=0.003)$. They also exhibited higher emotion coping than the healthy subjects $(\mathrm{p}=0.003)$ and lower seeking social support coping compared to $\mathrm{IBS}^{+}$patients $(\mathrm{p}=0.001)$. Interestingly, $\mathrm{IBS}^{+}$patients used significantly more social support searching strategies than the healthy subjects $(\mathrm{p}=0.01)$. A tendency was also observed for group heterogeneity for the internal scale $[\mathrm{H}(2$, $\mathrm{N}=46)=5.455534 ; \mathrm{p}=0.065]$ and "chance" external scale $[\mathrm{H}(2, \mathrm{~N}=46)=5.878844 ; \mathrm{p}=0.052]$. 
A difference among the groups was observed for LFn score [H (2, N=48)=15.02659; $\mathrm{p}<0.001]$, HFn $[\mathrm{H}(2, \mathrm{~N}=48)=19.32970 ; \mathrm{p}<0.001]$ and $\mathrm{LF} / \mathrm{HF}$ ratio $[\mathrm{H}(2, \mathrm{~N}=48)=14.70271$; $\mathrm{p}<0.001$, with IBS ${ }^{-}$patients having the highest LFn ( $\left.p=0.001\right)$, the lowest HFn $(p=0.0002)$ scores and obviously the highest $\mathrm{LF} / \mathrm{HF}$ ratio $(\mathrm{p}=0.001)$ as compared to the healthy subjects. No difference was observed among the groups for VLFn and HR.

\subsection{In-between pathology comparisons}

When comparing only patients with positive affects, differences among pathologies were observed for social support searching $[\mathrm{H}(2, \mathrm{~N}=36)=11.38878 ; \mathrm{p}=0.003]$ with $\mathrm{CD}^{+}$ $(\mathrm{p}=0.003)$ and $\mathrm{UC}^{+}(\mathrm{p}=0.04)$ patients having lower values than $\mathrm{IBS}^{+}$patients. Differences among groups were also noticed on $\mathrm{LH} / \mathrm{HF}$ ratio $[\mathrm{H}(2, \mathrm{~N}=37)=7.375762 ; \mathrm{p}=0.025]$ and $\mathrm{VLFn}$ [H (2, N= 37)=7.307977; $\mathrm{p}=0.025]$. Two by two comparisons showed that $\mathrm{CD}^{+}$patients differed from $\mathrm{UC}^{+}$patients on VLFn $(\mathrm{p}=0.02)$, while $\mathrm{UC}^{+}$patients had lower $\mathrm{LF} / \mathrm{HF}$ ratio than $\mathrm{IBS}^{+}$patients $(\mathrm{p}=0.002)$. No differences were observed for other variables.

When comparing all patients with negative affects, differences among pathologies were observed on "powerful others" external control $[\mathrm{H}(2, \mathrm{~N}=36)=7.463072 ; \mathrm{p}=0.024]$ with $\mathrm{CD}^{-}$patients having a slightly higher score than $\mathrm{IBS}^{-}$patients $(\mathrm{p}=0.06)$. Differences among pathologies were also noticed for $\operatorname{LFn}[\mathrm{H}(2, \mathrm{~N}=38)=7.280014 ; \mathrm{p}=0.026]$, $\mathrm{HFn}[\mathrm{H}(2$, $\mathrm{N}=38)=5.801725 ; \mathrm{p}=0.055]$ and $\mathrm{LF} / \mathrm{HF}$ ratio $[\mathrm{H}(2, \mathrm{~N}=38)=6.303644 ; \mathrm{p}=0.042]$. Two by two comparisons showed that $\mathrm{CD}^{-}$patients got lower LFn $(\mathrm{p}=0.02)$, higher $\mathrm{HFn}(\mathrm{p}=0.04)$ and lower $\mathrm{LF} / \mathrm{HF}$ ratio $\left(\mathrm{p}=0.03\right.$ ) than $\mathrm{IBS}^{-}$patients. No differences were observed for other variables. 


\section{Discussion}

The present study reveals that positive affective adjustment in patients with IBD (UC or CD) is associated to problem-focused coping strategies and adapted protective ANS activity. In IBS, the positive affective adjustment is also related to problem-focused coping strategies but ANS activity is not coupled to the psychological adjustment.

\subsection{Crohn's disease patients}

The CD patients with positive affective adjustment (i.e., low scores of: anxiety, depressive symptomatology, negative mood and perceived stress) developed positive coping strategies since $\mathrm{CD}^{+}$have a higher score in problem-focused coping and a lower score in emotion-focused coping than $\mathrm{CD}^{-}$patients. Concomitantly, $\mathrm{CD}^{+}$exhibited a higher level of sympathetic activity and a lower level of parasympathetic activity than healthy subjects. Such an autonomic imbalance is not surprising since recent studies have revealed that the sympathetic nervous system may exert protective anti-inflammatory effects in CD (Stasi and Orlandelli, 2008; Straub et al., 2008). Moreover, nicotine, a parasympathetic agonist, is known to be deleterious in CD patients (Cosnes, 2004) as well as in an experimental model of CD (Galeazzi et al., 1999). Therefore our results indicate a coupling between positive coping strategy and an enhanced sympathetic activity in $\mathrm{CD}^{+}$patients. Our results suggest that the interaction between perceived stress and avoidance coping recently reported in CD (Bitton et al., 2008) could be wider and would also involve a protective sympathetic adaptation of the sympatho-vagal balance. However, it should be outlined that ANS adaptation in positive coping represents a stress functioning with a higher biological cost explaining why CD patients generally report more anxiety and depression than UC patients (Nordin et al., 2002). 


\subsection{Ulcerative colitis patients}

The $\mathrm{UC}^{+}$sub-group of patients also showed more focused-problem coping strategies than the $\mathrm{UC}^{-}$subgroup. This was coupled to an equilibrated autonomic balance although their VLFn was lower than that observed in the healthy subjects. Such a pattern might reflect a long-term parasympathetic vulnerability as VLF, principally influenced by the renin-angiotensinaldosterone system, this depends primarily on the presence of parasympathetic outflow. Indeed, the blockade of adrenergic receptors does not change VLF spectrum, whereas the blockade of nicotinic receptors abolishes it (Taylor et al., 1998). Conversely, the UC ${ }^{-}$patients showed a higher emotion-focused coping score. Their parasympathetic tonus was acutely blunted as suggested by the diminished HFn power spectral band compared to the healthy subjects. So, here again, the ANS activity is coupled to the way patients cope with their disease. However, three points should be highlighted: (i) The normal sympathetic activity in $\mathrm{UC}^{+}$patients suggests that the ANS develops a reduced stress adaptation, with only a parasympathetic withdrawal, associated to positive coping and affective adjustment. Consequently, the biological cost for $\mathrm{UC}^{+}$seems lower than that observed in $\mathrm{CD}^{+}$. This is supported by the fact that CD patients with increased disease activity report a greater impaired health-related quality of life and emotional distress than UC patients (Larsson et al., 2008). (ii) The lower ANS stress reaction in $\mathrm{UC}^{+}$compared to $\mathrm{UC}^{-}$may reveal a higher parasympathetic tone bearing favourable activity. This is supported by the beneficial effect of nicotine in UC (Cosnes, 2004) and by data obtained from an animal model of UC (Ghia et al., 2007). This agrees with theories on the physiological protective role of vagal tone (Porges, 1995) and on the vagus cholinergic anti-inflammatory pathway (Pavlov and Tracey, 2005). 


\subsection{Irritable bowel syndrome patients}

As observed in IBD, IBS patients exhibited a coping behaviour in accordance with their emotional adjustment as $\mathrm{IBS}^{+}$patients presented higher problem-focused coping and social support searching scores than IBS ${ }^{-}$. This agrees with the fact that IBS women based their coping more on social resources and less on personal resources (Fouché et al., 2006). Concomitantly, we observed profound disturbances in the sympatho-vagal balance in all IBS patients as compared to the healthy subjects. This is in accordance with other studies reporting a persistent sympathetic dominance in IBS patients at rest (Orr et al., 2000) and under stress (Tanaka et al., 2008) together with a persistent parasympathetic hyporeactivity (Van Orshoven et al., 2006) and a severe vagal dysfunction (Spaziani et al., 2008). The fact that we did not find any statistical differences in autonomic balance between IBS $^{-}$and IBS $^{+}$patients could be due to a lack of statistical power linked to the small sample size. But this seems unlikely since we have found significant differences in IBD subgroups with similar sample sizes. Alternatively, the relative uncoupling of vagal tone with affective and coping behaviour merits discussion. IBS has been suggested to be mainly characterized by visceral hypersensitivity (Truong et al., 2008) and abnormal loci of brain activation to pain (Mayer et al., 2006; Mulak and Bonaz, 2004; Truong et al., 2008). The altered gut perception may induce false autonomic reflex responses to gut stimuli independently to the pathological status of the gut. Accordingly, in our study, diarrhoea-predominant IBS patients were equally dispatched in the $\mathrm{IBS}^{+}$and $\mathrm{IBS}^{-}$subgroups and we did not find a correlation between affective adjustment and bowel habits as it was shown in other experimental conditions (Spetalen et al., 2008). 


\subsection{Methodological considerations}

Comparisons among the diseases shed light on two main methodological points: (i) HRV analysis should not be isolated from the pathological mechanism (i.e., the pathology specificity) and the stress reaction, including psychobiological adjustment. In our sample, HRV parameters in CD and UC patients must be interpreted considering the negative or positive affects. Taken alone, HRV parameters may not provide a reliable conclusion about the nature of the adaptation of the autonomic balance. This aspect may explain contradictory results that could be found in the literature. Indeed, some studies found autonomic alterations only in UC and not in CD (Coruzzi et al., 2007; Ganguli et al., 2007), or in both (Mouzas et al., 2002) depending or not on the disease activity, quality of life or anxiety. Our results demonstrate further, that a set of negative affects (anxiety trait and state, negative mood, depressive symptomatology and perceived stress) with coping strategies influence the sympathetic/parasympathetic balance according to the specificities of each pathology. (ii) The behavioural adjustment observed in a given pathology is part of a more global adjustment corresponding to the equilibrium between the aggressor (i.e., the disease even if modulated by the environmental strain) and body changes due to coping. In our study, $\mathrm{CD}^{-}$had the highest score of "powerful others" external health locus of control while $\mathrm{CD}^{+}$patients had the lowest score for searching social support. This result is in accordance with the fact that CD patients exhibit a higher external locus of control than patients with IBS or chronic idiopathic constipation (Hobbis et al., 2003). As a counterpart, this may reflect that CD is perceived by the individual as uncontrollable. The perception of control over the illness obviously depends on the pathology and its severity. In our groups, IBS patients exhibited the opposite pattern than those of CD patients, a result that agrees with another study showing an interaction between emotional distress and coping strategy in IBS patients (Rutter and Rutter, 2002). Studies taking into account disease controllability according to the type of intestinal 
pathology are rare, although this concept is one of the most important in the transactional model of stress (Lazarus and Folkman, 1984). Even if IBD and IBS present different aetiology and pathophysiology, they share some common psychological features due to their chronicity, revealing that IBD and IBS are biopsychosocial models as currently stated for IBS (Camilleri, 2001; Mulak and Bonaz, 2004) and more recently proposed for IBD (Bitton et al., 2008; Pigeon-Reesor and Ottawa, 2008).

To conclude, this study suggests that the equilibrium of the ANS is differentially adapted according to the disease. This equilibrium is coupled with affective and cognitive positive adjustment in IBD but not in IBS. This raises the question of individual stress vulnerability in IBS or IBD patients. For a better understanding of the physiological, emotional and cognitive mechanisms of individual stress vulnerability, experimental and controlled-design studies are now required in this field. 


\section{References}

Akselrod, S., Gordon, D., Ubel, F.A., Shannon, D.C., Barger, A.C., Cohen, R.J., 1981. Power spectrum analysis of heart rate fluctuation: a quantitative probe of beat-to-beat cardiovascular control. Science 213, 220-222.

Baumgart, D.C., Sandborn, W.J., 2007. Inflammatory bowel disease: clinical aspects and established and evolving therapies. The Lancet 369, 1641-1657.

Benarroch, E.E., 1993. The central autonomic network: functional organization, dysfunction and perspective. Mayo Clinic Proceedings 68, 988-1001.

Bitton, A., Dobkin, P.L., Edwardes, M.D., Sewitch, M.J., Meddings, J.B., Rawal, S., Cohen, S., Vermeire, S., Dufresne, L., Franchimont, D., Wild, G.E., 2008. Predicting relapse in Crohn's disease: a biopsychosocial model. Gut 57, 1386-1392.

Bruchon-Schweitzer, M., Paulhan, I., 1993. Manuel de l'inventaire d'anxiété état-trait forme Y (STAI-Y). Adapté par Bruchon-Schweitzer et Paulhan. Paris.

Camilleri, M., 2001. Management of the irritable bowel syndrome. Gastroenterology 120, 652-668.

Chen, C.L., Lin, H.H., Orr, W.C., Yang, C.C.H., Kuo, T.B.J., 2004. Transfer function analysis of heart rate variability in response to water intake: correlation with gastric myoelectrical activity. J. Appl. Physiol. 96, 2226-2230.

Chen, C.L., Orr, W.C., Yang, C.C.H., Kuo, T.B.J., 2006. Cardiac autonomic regulation differentiates reflux disease with and without erosive esophagitis. Scand J Gastroenterol 41, 1001-1006.

Coffin, B., Bouhassira, D., Sabaté, J.M., Barbe, L., Jian, R., 2004. Alteration of the spinal modulation of nociceptive processing in patients with irritable bowel syndrome. Gut 53, $1465-1470$. 
Cohen, M.E., 1983. Mental health administration (factors which indicate success on the job). Journal of Mental Health Administration 10, 10-12.

Collins, S.M., 2001. Stress and the gastrointestinal tract IV: modulation of intestinal inflammation by stress: basic mechanisms and clinical relevance. American Journal of Physiology and Gastrointestinal and Liver Physiology 280, G315-G1044.

Coruzzi, P., Castiglioni, P., Parati, G., Brambilla, V., Brambilla, L., Gualerzi, M., Cademartiri, F., Franzè, A., De Angelis, G., Di Rienzo, M., Di Mario, F., 2007. Autonomic cardiovascular regulation in quiescent ulcerative colitis and Crohn's disease. European Journal of Clinical Investigation 37, 964-970.

Cosnes, J., 2004. Tobacco and IBD: relevance in the understanding of disease mechanisms and clinical practice. Best Practice and Research Clinical Gastroenterology 18, 481-496.

Cousson, F., Bruchon-Schweitzer, M., Quintard, B., Nuissier, J., Rascle, N., 1996. Analyse multidimensionnelle d'une échelle de coping: validation française de la WCC (Ways of Coping Checklist). Psychologie Française 41, 155-164.

Craig, A.D.B., 2002. How do you feel? Interoception: The sense of the psychological condition of the body. Nature Review of Neuroscience 3, 655-666.

Fouché, P., Gouws, C., Cloete, P., Naidoo, S., 2006. Biopsychosocial coping and adjustment of adult female irritable syndrome patients. South African Journal of Psychology 36, 780794.

Fuhrer, R., Rouillon, F., 1989. Fuhrer, R, Rouillon F. La version française de l'échelle CES-D (Center for Epidemiologic Studies-Depression Scale). Description et traduction de l'échelle d’autoévaluation Psychiatry and Psychobiology 4, 163-166.

Galeazzi, F., Blennerhassett, P.A., Qiu, B., O’Byrne, P.M., Collins, S.M., 1999. Cigarette Smoke Aggravates Experimental Colitis in Rats. Gastroenterology 117, 877-883. 
Ganguli, S.C., Kamath, M.V., Redmond, K., Chen, Y., Irvine, E.J., Collins, S.M., Tougas, G., 2007. A comparison of autonomic function in patients with inflammatory bowel disease and in healthy healthy controls. Neurogastroenterology and Motility 19, 961-967.

Ghia, J.E., Blennerhassett, P., Collins, S.M., 2007. Vagus nerve integrity and experimental colitis. The American Journal of Physiology Gastrointestinal Liver Physiology 293, G560-567.

Gillanders, S., Wild, M., Deighan, C., Gillanders, D., 2008. Emotion regulation, affect, psychosocial functioning, and well-being in hemodialysis patients. American Journal of Kidney Disease 51, 651-662.

Harvey, R.F., Bradshaw, J.M., 1980. A simple index of Crohn's disease activity. Lancet 1, 514.

Hobbis, C.A., Turpin, G., Read, N.W., 2003. Abnormal illness behaviour and locus of control in patients with functional bowel disorders. British Journal of Health Psychology 8, 393408.

Jarrett, M.E., Burr, R.L., Cain, K.C., Rothermel, J.D., Landis, C.A., Heitkemper, M.M., 2008. Autonomic nervous sysytem function during sleep among women with irritable bowel syndrome. Dig Dis Sci 53, 694-703.

Jones, M.P., Wessinger, S., Crowell, M.D., 2006. Coping strategies and interpersonal support in patients with irritable bowel syndrome and inflammatory bowel disease. Clinical Gastroenterology and Hepatology 4, 474-481.

Larsson, K., Lööf, L., Rönnblom, A., Nordin, K., 2008. Quality of life for patients with exacerbation in inflammatory bowel disease and how they cope with disease activity Journal of Psychosomatic Research 64, 139-148.

Lazarus, R.S., Folkman, S., 1984. Stress, Appraisal and Coping. Springer, New York:. 
Li, J., Nørgard, B., Precht, D.H., Olsen, J., 2004. Psychological stress and inflammatory bowel disease: a follow-up study in parents who lost a child in Denmark. American Journal of Gastroenterology 99, 1129-1133.

Loewy, A., Spyer, K., 1990. Central regulation of autonomic functions. Oxford University Press, New York.

Lombardi, F., Malliani, A., Pagani, M., Cerutti, S., 1996. Heart rate variability and its sympatho-vagal modulation. Cardiovascular Research 32, 208-216.

Martz, E., Livneh, H., 2007. Coping with Chronic Illness and Disability. Theoretical, Empirical and Clinical Aspects. Springer, New York.

Mawdsley, J.E., Rampton, D.S., 2005. Psychological stress in IBD: new insights into pathogenic and therapeutic implications. Gut 54, 1481-1491.

Mayer, E.A., Naliboff, B.D., Craig, A.D.B., 2006. Neuroimaging of the brain-gut axis: from basic understanding to treatment of functional GI disorders. Gastroenterology 131, 19251942.

Miehsler, W., Weichselberger, M., Offerlbauer-Ernst, A., Dejaco, C., Reinisch, W., Vogelsang, H., Machold, K., Stamm, T., Gangl, A., Moser, G., 2008. Which patients with IBD need psychological interventions? A controlled study. Inflammatory Bowel Disease 14, 1273-1280.

Mittermaier, C., Dejaco, C., Waldhoer, T., Oefferlbauer-Ernst, A., Miehsler, W., Beier, M., Tillinger, W., Gangl, A., Moser, G., 2004. Impact of depressive mood on relapse in patients with inflammatory bowel disease: A prospective 18-month follow-up study. Psychosomatic Medecine 66, 79-84.

Mönnikes, H., Tebbe, J.J., Hildebrandt, M., Arck, P., Osmanoglou, E., Rose, M., Klapp, B., Wiedenmann, B., Heymann-Mönnikes, I., 2001. Role of stress in functional 
gastrointestinal disorders. Evidence for stress-induced alterations in gastrointestinal motility and sensitivity. Digestive Disease 19, 201-211.

Mouzas, I.A., Pallis, A.G., Kochiadakis, G.E., Marketou, M., Chlouverakis, G.I., Mellisas, J., Vardas, P.E., Kouroumalis, E.A., 2002. Autonomic imbalance during the day in patients with inflammatory bowel disease in remission. Evidence from spectral analysis of heart rate variability over 24 hours. Digestive and Liver Disease 34, 775-780.

Mulak, A., Bonaz, B., 2004. Irritable bowel syndrome: a model of the brain-gut interactions. Medical science monitor 10, 55-62.

Ng, C., Malcolm, A., Hansen, R., Kellow, J., 2007. Feeding and colonic distention provoke autonomic responses in irritable bowel syndrome. Scand J Gastroenterol 42, 441-446.

Nordin, K., Pahlman, L., Larsson, K., Sundberg-Hjelm, M., Lööf, L., 2002. Health-related quality of life and psychological distress in a population-based sample of Swedish patients with inflammatory bowel disease. Scand J Gastroenterol 37, 450-457.

Nunnally, J.C., 1978. Psychometric theory. New York.

Olden, K.W., 2008. Psychological factors in functional gastrointestinal disorders: an evolving phenomenon. Neurogastroenterology and Motility 20, 114-120.

Ollsson, B., Sundkvist, G., Lindgren, S., 2007. Subclinical sympathetic neuropathy appears early in the course of Crohn's disease. BMC Gastroenterology 7, 1-6.

Orr, W.C., Elsenbruch, S., Harnish, M.J., 2000. Autonomic regulation of cardiac function during sleep in patients with irritable bowel syndrome. American Journal of Gastroenterology 95, 2865-2871.

Pavlov, V.A., Tracey, K.J., 2005. The cholinergic anti-inflammatory pathway. Brain Behavior and Immunity 19, 493-499. 
Petelenz, M., Gonciarz, M., Macfarlane, P., Rudner, R., Kawecki, P., Musialik, J., Jalowiecki, P., Gonciarz, Z., 2004. Sympathovagal balance fluctuates during colonoscopy. Endoscopy 36, 508-514.

Pigeon-Reesor, H., Ottawa, U., 2008. A comparison of Irritable Bowel Syndrome and Crohn's disease: machanisms underlying symptom processing and sickness impact. Dissertation Abstracts International: Sectioin B: The Sciences and Engineering 68, 4880.

Porges, S.W., 1995. Cardiac vagal tone: a physiological index of stress. Neuroscience and Biobehavioral Review 19, 225-233.

Radloff, L.S., 1977. The CES-D scale: A self-report depression scale for research in the general population. Applied Psychological Measurement 3, 385-401.

Reber, S.O., Obermeier, F., Straub, R.H., Falk, W., Neumann, I.D., 2006. Chronic intermittent psychosocial stress (social defeat/overcrowding) in mice increases the severity of an acute DSS-induced colitis and impairs regeneration. Endocrinology 147, 4968-4976.

Rogala, L., Miller, N., Graff, L.A., Rawsthorne, P., Clara, I., Walker, J.R., Lix, L., Ediger, J.P., McPhail, C., Bernstein, C.N., 2008. Population-based controlled study of social support, self-perceived stress, activity and work issues, and access to health care in inflammatory bowel disease. Inflammatory Bowel Disease 14, 526-535.

Rutter, C.L., Rutter, D.R., 2002. Illness representation, coping and outcome in irritable bowel syndrome (IBS). British Journal of Health Psychology 7, 377-391.

Saper, C.B., 2002. The central autonomic nervous system: conscious visceral perception and autonomic pattern generation. Annual Review of neuroscience 25, 433-469.

Schepper, H.U., De Man, J.G., Moreels, T.G., Pelckmans, P.A., De Winter, B.Y., 2008. Review article: gastrointestinal sensory and motor disturbances in inflammatory bowel disease-clinical relevance and pathophysiological mechanisms. Alimentary Pharmacology and Therapeutics 27, 621-637. 
Seminowicz, D.A., Mikulis, D.J., Davis, K.D., 2004. Cognitive modulation of pain-related brain responses depends on behavioral strategy. Pain 112, 48-58.

Sharma, P., Makharia, G.K., Ahuja, V., Dwivedi, S.N., Deepak, K.K., 2009. Autonomic dysfunctions in patients with inflammatory bowel disease in clinical remission. Dig Dis Sci 54, 853-861.

Spaziani, R., Bayati, A., Redmond, K., Bajaj, H., Bienenstock, J., Collins, S.M., Kamath, M.V., 2008. Vagal dysfunction in irritable bowel syndrome assessed by rectal distensioni and baroreceptor sensitivity. Neurogastroenterol Motil 20, 336-342.

Spetalen, S., Sandvik, L., Blomhoff, S., M.B., J., 2008. Autonomic function at rest and in response to emotional and rectal stimuli in women with irritable bowel syndrome. Dig Dis Sci 53, 1652-1659.

Stasi, C., Orlandelli, E., 2008. Role of the brain-gut axis in the pathophysiology of Crohn's disease. Digestive Disease 26, 156-166.

Straub, R.H., Grum, F., Strauch, U., Capellino, S., Bataille, F., Bleich, A., Falk, W., Schölmerich, J., Obermeier, F., 2008. Anti-inflammatory role of sympathetic nerves in chronic intestinal inflammation. Gut 57, 911-921.

Sugaya, N., Nomura, S., 2008. relationship between cognitive appraisals of symptoms and negative mood for subtypes of irritable bowel syndrome. BioPsychoSocial Medecine 2, $1-6$.

Tanaka, T., Manabe, N., Hata, J., Kusunoki, H., Ishii, M., Sato, M., Kamada, T., Shiotani, A., Haruma, K., 2008. Characterization of autonomic dysfunction in patients with irritable bowel syndrome using fingertip blood flow. Neurogastroenterology and Motility 20, 498504. 
Tang, L.Y., Nabalamba, A., Graff, L.A., Bernstein, C.N., 2008. A comparison of selfperceived health status in inflammatory bowel disease and irritable bowel syndrome patients from a Canadian national population survey. Canadian Journal of Gastroenterology 22, 475-483.

Taylor, C.T., Keely, S.J., 2007. The autonomic nervous system and inflammatory bowel disease. Autonomic Neuroscience 133, 104-114.

Taylor, J.A., Carr, D.L., Myers, C.W., Eckberg, D.L., 1998. Mechanisms underlying verylow-frequency RR-interval oscillations in humans. Circulation 98, 547-555.

Thompson, R.J., Gustafson, K.E., 1996. Adaptation to chronic childhood illness. American Psychological Association, Washington DC.

Thompson, W.G., Heaton, K.W., Smyth, G.T., Smyth, C., 2000. Irritable bowel syndrome in general practice: prevalence, characteristics, and referral. In, Gut. pp. 78-82.

Thompson, W.G., Longstreth, G.F., Drossman, D.A., Heaton, K.W., Irvine, E.J., MüllerLissner, S.A., 1999. Functional bowel disorders and functional abdominal pain. Gut 45, 43-47.

Truong, T.T., Naliboff, B.D., Chang, L., 2008. Novel techniques to study visceral hypersensitivity in irritable bowel syndrome. Current Gastroenterology Reports 10, 369378.

Van Orshoven, N.P., Andriesse, G.I., Van Schelven, L.J., Smout, A.J., Akkermans, L.M., Oey, P.L., 2006. Subtle involvement of the parasympathetic nervous system in patients with irritable bowel syndrome. Clinical Autonomic research 16, 33-39.

Vitaliano, P.P., Russo, J., Carr, J.E., Maiuro, R.D., Maiuro, R.D., Becker, J., 1985. The Ways of Coping Checklist: revision and psychometric properties. 1985; 20: 3-26. Multivariate Behavioral Research 20, 3-26. 
Von Stein, P., Lofberg, R., Kuznetsov, N.V., Gielen, A.W., Persson, J.O., Sundberg, R., Von Stein, O.D., 2008. Multigene analysis can discriminate between ulcerative colitis, Crohn's disease and irritable bowel syndrome. Gastroenterology 134, 1869-1881.

Wallston, K.A., Wallston, B.S., DeVellis, R., 1978. Development of the Multidimensional Health Locus of Control (MHLC) Scales. Health Education Monography 6, 160-170.

Watson, D., Clark, L.A., Tellegen, A., 1988a. Development of a brief measure of positive and negative affect : the PANAS scales. Journal of Personality and Social Psychology 54, 1063-1070. 
Table 1. Subject demographics.

\begin{tabular}{|c|c|c|c|c|}
\hline & Healthy & CD & & IBS \\
\hline $\begin{array}{l}\text { Total number of } \\
\text { subjects }\end{array}$ & 21 & 26 & 22 & 27 \\
\hline Mean age-yr (sem) & $39 \pm 12$ & $43 \pm 14$ & $42 \pm 16$ & $40 \pm 14$ \\
\hline Sex-M/F & $8 / 13$ & $8 / 18$ & $9 / 13$ & $9 / 18$ \\
\hline $\begin{array}{l}\text { Mean duration of } \\
\text { disease-yr (range) }\end{array}$ & & $14.2(4-29)$ & $10.7(2-32)$ & $9.1(1-21)$ \\
\hline $\begin{array}{l}\text { IBS } \\
\text { - Low abdominal pain } \\
\text { (VAS }<5 / 10) \\
\text { - High abdominal } \\
\text { pain }(\text { VAS }>5 / 10)\end{array}$ & & & & $\begin{array}{c}20 \\
7\end{array}$ \\
\hline \begin{tabular}{ll} 
IBD & \\
Inactive disease \\
$-\quad$ Mean HBI (range) \\
$-\quad$ Mean Lichtiger's \\
\multicolumn{1}{c}{ score (range) } \\
Active disease \\
$-\quad$ Mean HBI (range) \\
$-\quad$ Mean Lichtiger's \\
$\quad$ score (range)
\end{tabular} & & $\begin{array}{c}21 \\
0.7(0-4) \\
\\
\\
5 \\
8(6-11)\end{array}$ & $\begin{array}{c}16 \\
3.2(1-7) \\
6 \\
12.2(11-13)\end{array}$ & \\
\hline $\begin{array}{l}\text { Disease location } \\
\text { Colitis } \\
\text { Ileitis } \\
\text { Ileo-colitis } \\
\text { Pancolitis } \\
\text { Left-sided colitis }\end{array}$ & & $\begin{array}{c}10 \\
8 \\
8\end{array}$ & $\begin{array}{c}6 \\
16 \\
\end{array}$ & \\
\hline Smoker (n) & & 4 & 1 & \\
\hline $\begin{array}{ll}\text { Treatment on inclusion: } \\
\text { no. of patients (mean } \\
\text { dose) } \\
\text { - } \text { Mesalamine } \\
-\quad \text { Prednisone } \\
-\quad \text { Budesonide } \\
\text { - } & \text { Azathioprine/6- } \\
& \text { MP } \\
- & \text { Methotrexate } \\
- & \text { Infliximab (each } 8 \\
\text { - } & \text { Aeeks) } \\
- & \text { Antispamodiciarrheic }\end{array}$ & & $\begin{array}{c}2(2 \mathrm{~g}) \\
1(30 \mathrm{mg}) \\
1(6 \mathrm{mg}) \\
18(150 \mathrm{mg}) \\
3(15 \mathrm{mg}) \\
1(5 \mathrm{mg} / \mathrm{kg} \mathrm{iv})\end{array}$ & $\begin{array}{l}13(2,5 g) \\
3(30 \mathrm{mg}) \\
6(150 \mathrm{mg})\end{array}$ & $\begin{array}{l}2 \\
2\end{array}$ \\
\hline
\end{tabular}


Table 2. Descriptive variables (mean \pm sem) of the positive and negative affective adjustments in healthy subjects and patients, corresponding to the principle factor of affective adjustment. This factor includes several affective variables representative of anxiety, negative mood, depressive symptomatology and perceived stress. Patients presenting a low score on this principle factor are considered as positively adjusted and those with a high score are negatively adjusted (see Mat\&Met for more precisions)

\begin{tabular}{|c|c|c|c|c|c|c|c|}
\hline & Healthy & CD & & UC & & IBS & \\
\hline & $\mathrm{N}=21$ & $\begin{array}{l}\mathrm{CD}^{+} \\
\mathrm{N}=13\end{array}$ & $\begin{array}{l}\mathrm{CD}^{-} \\
\mathrm{N}=8\end{array}$ & $\begin{array}{l}\mathrm{UC}^{+} \\
\mathrm{N}=13\end{array}$ & $\begin{array}{l}\mathrm{UC}^{-} \\
\mathrm{N}=9\end{array}$ & $\begin{array}{l}\mathrm{IBS}^{+} \\
\mathrm{N}=10\end{array}$ & $\begin{array}{l}\mathrm{IBS}^{-} \\
\mathrm{N}=17\end{array}$ \\
\hline STAI-trait & $42.95 \pm 1.41$ & $35.85 \pm 1.60$ & $55.08 \pm 2.07$ & $38.92 \pm 2.03$ & $53.22 \pm 1.43$ & $40.33 \pm 1.46$ & $56.58 \pm 1.58$ \\
\hline STAI-state & $33.76 \pm 2.21$ & $30.50 \pm 1.39$ & $48.41 \pm 3.44$ & $31.30 \pm 1.71$ & $52.77 \pm 3.30$ & $32.40 \pm 2.06$ & $47.94 \pm 2.86$ \\
\hline CES-D & $8.57 \pm 1.19$ & $7.71 \pm 1.22$ & $25.58 \pm 2.89$ & $12.30 \pm 2.17$ & $23.88 \pm 2.63$ & $8.60 \pm 1.40$ & $26.88 \pm 2.87$ \\
\hline PANAS & $20.80 \pm 1.81$ & $19.42 \pm 1.50$ & $29.83 \pm 1.41$ & $19.61 \pm 1.06$ & $30.44 \pm 2.62$ & $21.90 \pm 1.10$ & $30.35 \pm 1.92$ \\
\hline PSS & $34.95 \pm 1.54$ & $30.78 \pm 1.62$ & $47.75 \pm 1.67$ & $35.53 \pm 1.17$ & $44.22 \pm 2.77$ & $31.60 \pm 1.92$ & $43.76 \pm 1.35$ \\
\hline
\end{tabular}


Table 3. Physiological and psychological parameters in IBD and IBS patients (with positive and negative affects) and healthy subjects. Results are expressed as mean \pm standard deviation. ${ }^{\text {a }}$ significant differences between patients (CD, UC, IBS) with positive or negative affect and healthy subjects; ${ }^{\mathbf{b}}$ significant differences between subgroups of patients (positive versus negative); ${ }^{\mathbf{c}}$ significant differences in-between pathologies with positive affect; ${ }^{\mathbf{d}}$ significant differences in-between pathologies with negative affect. Statistical differences are detailed in the text.

\begin{tabular}{|c|c|c|c|c|c|c|c|}
\hline & \multirow[t]{2}{*}{ Healthy } & \multicolumn{2}{|c|}{ Crohn's Disease } & \multicolumn{2}{|c|}{ Ulcerative Colitis } & \multicolumn{2}{|c|}{ Irritable Bowel Syndrome } \\
\hline & & $\mathbf{C D}^{+}$ & $\mathbf{C D}^{-}$ & $\mathbf{U C}^{+}$ & $\mathbf{U C}^{-}$ & IBS $^{+}$ & IBS $^{-}$ \\
\hline \multicolumn{8}{|l|}{ WCC coping scores } \\
\hline Problem-centred & $31.5 \pm 2.7$ & $32.1 \pm 2.3^{b}$ & $29.2 \pm 2.9$ & $32.2 \pm 3.4^{b}$ & $27.8 \pm 4.2$ & $33.2 \pm 3.7^{b}$ & $26.4 \pm 6.1^{\mathrm{a}}$ \\
\hline emotion-centred & $20.5 \pm 3.6$ & $20.2 \pm 3.9^{b}$ & $24.9 \pm 3.9^{\mathrm{a}}$ & $20.5 \pm 5.3$ & $24.4 \pm 1.4^{\mathrm{a}}$ & $22.1 \pm 3.1$ & $24.7 \pm 3.7^{\mathrm{a}}$ \\
\hline social support ${ }^{\mathrm{C}}$ & $22.7 \pm 3.2$ & $21.7 \pm 3.5$ & $21.3 \pm 5.2$ & $23 \pm 3.98$ & $21.1 \pm 4.4$ & $27.5 \pm 3.2^{\mathrm{ab}}$ & $20.7 \pm 5$ \\
\hline \multicolumn{8}{|l|}{ Health Locus of control } \\
\hline Internal scores & $16.5 \pm 2$ & $15.4 \pm 1.8$ & $15.8 \pm 1.8$ & $16 \pm 2.5$ & $14.5 \pm 1.6^{\mathrm{a}}$ & $16.7 \pm 2.5$ & $15.3 \pm 2.6$ \\
\hline Powerful others scores ${ }^{d}$ & $11.7 \pm 2.3$ & $14.2 \pm 2.4^{\mathrm{a}}$ & $14.7 \pm 2.6^{\mathrm{a}}$ & $14 \pm 3.3$ & $14.7 \pm 2.6^{\mathrm{a}}$ & $13.5 \pm 4.5$ & $12.1 \pm 2.4$ \\
\hline Chance scores & $13.4 \pm 1.8$ & $12.4 \pm 2.8$ & $14.1 \pm 2.8$ & $12 \pm 2.5$ & $12.6 \pm 2.1$ & $11.6 \pm 2.9$ & $11.9 \pm 2.1$ \\
\hline \multicolumn{8}{|l|}{ Heart Rate Variability } \\
\hline $\mathrm{HR}$ & $69.9 \pm 8.6$ & $76.7 \pm 10.7$ & $73.2 \pm 8.7$ & $75.1 \pm 15.1$ & $78 \pm 12.8$ & $74.7 \pm 10$ & $70 \pm 8.2$ \\
\hline LFn ${ }^{d}$ & $48 \pm 10.9$ & $59.2 \pm 12.4^{\mathrm{a}}$ & $52.1 \pm 10.8$ & $47.6 \pm 18.1$ & $59.08 \pm 12.6$ & $64.6 \pm 17.2^{\mathrm{a}}$ & $65.2 \pm 14.1^{\mathrm{a}}$ \\
\hline HFn ${ }^{d}$ & $48.1 \pm 10.9$ & $34.8 \pm 13.3^{\mathrm{a}}$ & $40 \pm 12.5$ & $44.2 \pm 14.7$ & $34.2 \pm 14.1^{\mathrm{a}}$ & $28.7 \pm 18.8^{\mathrm{a}}$ & $28.4 \pm 10.4^{\mathrm{a}}$ \\
\hline $\mathrm{LF} / \mathrm{HF}^{\mathrm{cd}}$ & $1.2 \pm 0.5$ & $2.2 \pm 1.8$ & $1.4 \pm 0.6$ & $1.2 \pm 0.8$ & $2.2 \pm 1.4$ & $3.8 \pm 3.2^{\mathrm{a}}$ & $2.8 \pm 1.8^{\mathrm{a}}$ \\
\hline VLFn $^{c}$ & $0.9 \pm 0.05$ & $0.9 \pm 0.06$ & $0.9 \pm 0.07$ & $0.8 \pm 0.08$ & $0.8 \pm 0.2$ & $0.8 \pm 0.1$ & $0.8 \pm 0.2$ \\
\hline
\end{tabular}

